\section{Journal of Medical Microbiology and Infectious Diseases}

JIOMMMIIID)

ISSN: $2345-5349$

eISSN: $2345-5330$

\title{
Comparison of Cysteine Protease B Gene Expression between Clinical Isolates of Leishmania tropica, Leishmania major and Leishmania infantum
}

\author{
Elham Kazemirad ${ }^{1}$, Hossein Reisi Nafchi ${ }^{1,2}$, Alireza Latifi ${ }^{1}$, Reza Raoofian $^{3}$, Mehdi Mohebali ${ }^{1,4}$, Homa \\ Hajjaran $^{1,5 *}$
}

${ }^{1}$ Department of Medical Parasitology and Mycology, School of Public Health, Tehran University of Medical Sciences, Tehran, Iran; ${ }^{2}$ Institute of biomedicine, Sahlgrenska Academy, University of Gothenberg, Gothenberg, Sweden; ${ }^{3}$ Legal Medicine Research Center, Legal Medicine Organization, Tehran, Iran; ${ }^{4}$ Research Center for Endemic Parasites of Iran, Tehran University of Medical Sciences, Tehran, Iran; ${ }^{5}$ Research center for Zoonoses, Parasitic and Microbial Diseases, Ardabil University of Medical Sciences, Ardabil, Iran

\begin{tabular}{|c|c|}
\hline A R T I C LE I NFO & A B S T R A C T \\
\hline riginal Article & $\begin{array}{l}\text { Introduction: Leishmania cysteine protease } \mathrm{B}(\mathrm{CPB}) \text { is a parasite virulence factor that } \\
\text { plays a vital role in host-parasitic interactions. Regarding the importance of the CPB }\end{array}$ \\
\hline $\begin{array}{lrr}\text { Keywords: } & \text { Cysteine } & \text { protease B } \\
\text { (CPB), } & \text { Real-time } & \text { RT-PCR, } \\
\text { Leishmania } & \text { species, Iran } & \end{array}$ & $\begin{array}{l}\text { gene, we used a quantitative real-time RT-PCR to investigate the expression of CPB in } \\
\text { the Iranian isolates of different Leishmania species. Methods: In this study, } 36 \text { clinical } \\
\text { samples were collected, out of which } 29 \text { belonged to cutaneous leishmaniasis (CL), } 3 \\
\text { to viscerotropic leishmaniasis (VTL), and } 5 \text { to visceral leishmaniasis (VL) patients. }\end{array}$ \\
\hline $\begin{array}{l}\text { Received: Oct. 05, } 2019 \\
\text { Received in revised form: Dec. 17, } \\
2019 \\
\text { Accepted: Dec. } 17,2019 \\
\text { DOI: } 10.29252 / J \text { MMID.7.3.72 }\end{array}$ & $\begin{array}{l}\text { Among CL isolates, } 8 \text { were Leishmania major, and } 21 \text { were Leishmania tropica, } \\
\text { including } 3 \text { isolates from the lupoid type. After RNA extraction and cDNA synthesis, } \\
\text { gene expression analysis was performed by qPCR. Results: Our results showed the } \\
\text { highest expression of CPB in isolates of Leishmania infantum, followed by L. major } \\
\text { and L. tropica. Among L. tropica isolates, in the lupoid forms, the mean expression of }\end{array}$ \\
\hline $\begin{array}{l}\text { *Correspondence } \\
\text { Email: hajaranh@tums.ac.ir } \\
\text { Tel: +98 } 2188951392 \\
\text { Fax: +98 } 2188951392\end{array}$ & $\begin{array}{l}\mathrm{CPB} \text { was } \approx 6.4 \text { times higher than that of non-lupoid isolates. In } L . \text { major isolates, a } \\
\text { significant difference was observed between the level of gene expression and the } \\
\text { duration of the infection. The expression level of CPB was associated with the severity } \\
\text { of the infection in } L \text {. infantum isolates. Conclusion: The CPB gene expressed in all } \\
\text { Leishmania species. The highest expression was in } L \text {. infantum species and the least } \\
\text { expression in } L \text {. tropica. The transcript level of CPB increased in } L \text {. major isolates } \\
\text { derived from patients with a higher number and duration of ulcers; however, further } \\
\text { studies on more clinical samples are needed to explore our findings. }\end{array}$ \\
\hline
\end{tabular}

\section{INTRODUCTION}

Leishmania is a flagellate intracellular parasite that causes a group of diseases called leishmaniasis. The disease is prevalent in tropical and Mediterranean countries and affects between 12 and 15 million people around the world annually [1]. Depending on the causative species and immunological status of the host, it can manifest as selfhealing cutaneous leishmaniasis (CL), diffuse cutaneous leishmaniasis (DCL), mucocutaneous leishmaniasis (MCL) and visceral leishmaniasis (VL) [2]. In the old world, including Iran, CL is mainly caused by Leishmania tropica, Leishmania major, and the species Leishmania infantum is the agent for visceral leishmaniasis [3]. The outcome of Leishmania infection depends on both host and pathogen factors that are implicated in the establishment of infection. Over the last decades, several components have been considered as virulence factors that contribute to the pathogenesis of parasite, enabling it for tissue invasion and survival in macrophages [1]. These antigenic compounds include glycoprotein 63 (GP63), lipophosphoglycan (LPG), glycosylphosphatidylinositol (GPI), Cysteine Proteases, metalloproteases, viscerotropic gene, and protein A2 [4]. Cysteine proteases (CPs) are considered as therapeutic targets due to their involvement in the biological processes during various stages of the parasite life cycle [5]. These enzymes are peptidyl hydrolyzes and classified according to their function and catalytic site [6]. Parasite cysteine proteases have been implicated in several processes such as differentiation, nutrition, host cell infection, and evasion of the host immune response [7,8]. Three classes of CPs, including type I (CPB), II (CPA), and III (CPC) have been well described in Leishmania spp [9]. The CPC and CPA have single genes while CPB genes are multicopy arranged in tandem arrays and characterized by the presence of a long C-terminal extension (CTE) rich in proline, serine and/or 
threonine residues $[5,9,10]$.

In different species of Leishmania, the number and sequence of the CPB gene are different. In Leishmania mexicana, $\mathrm{CPB}$ is located in one locus with 19 copies arranged in a tandem repeat. However, in the Leishmania donovani complex, there are five copies of it $[11,12]$. CPB is a cathepsin L-like protein that plays a vital role in hostparasitic interactions and immune invasion [5, 10]. The generation of $\mathrm{CP}$-deficient mutants showed that $\mathrm{CPB}$ contributes to parasite infection of macrophages and induce lesions in BALB/c mice [11]. In Iran, CPB and CPA from $L$. major and $L$. infantum were cloned and characterized, and have been confirmed to elicit a protective response in the form of recombinant proteins and in a DNA vaccine [13, 14]. It has been reported that a cocktail vaccine containing CPA and $\mathrm{CPB}$ encoding plasmids induces long-lasting protection against the L. major in the mouse model [15]. On the other hand, reaction of recombinant form of $\mathrm{CPA}$ and $\mathrm{CPB}$ with the sera of active and recovered VL cases from humans and dogs can suggest these antigens as diagnostic markers [16]. In particular, $\mathrm{CPB}$ and its long C-terminal extension (CTE) showed a higher level of IgG reactivity in asymptomatic dogs than in dogs with VL proposing their importance in serodiagnostic of asymptomatic form [17]. CPB is mostly expressed in the amastigote stage and to lesser extent in infective metacyclic promastigote [18]. However, there is not any study regarding the RNA transcript expression of $\mathrm{CPB}$ in promastigote form. According to the critical role of $\mathrm{CPB}$ in the pathogenesis and immune invasion [4], in the current study we evaluated the expression of cysteine protease B gene (CSB) in different isolates of L. tropica, $L$. major and $L$. infantum, exhibiting different clinical symptoms, in Iran using quantitative Real-Time PCR method. This study aimed to investigate the association between different Leishmania species and the expression level of CPB gene.

\section{MATERIAL AND METHODS}

In this study, 36 clinical samples were collected, out of which 29 belonged to cutaneous leishmaniasis, 5 belonged to visceral leishmaniasis, and 3 belonged to viscerotropic leishmaniasis. Among CL isolates, 21 were L. tropica, including three lupoid forms, and 8 were L. major. These samples were collected from patients who referred to the leishmaniasis Lab of School of Public Health, Tehran University of Medical Sciences (TUMS). The lupoid samples were isolated from patients who were diagnosed with a positive serum using DAT for more than two years. Visceral specimens included $5 \mathrm{~L}$. infantum and 3 viscerotropic L. tropica isolates, which were cryopreserved in the laboratory and previously diagnosed with a positive serum using DAT (Table 1).

Table 1. Number of isolates from different Leishmania species

\begin{tabular}{l|ll}
\hline \multicolumn{1}{l}{ Diseases } & Number of samples (Total no. $=36)$ & Kind of species \\
\hline $\begin{array}{l}\text { Cutaneous leishmaniasis } \\
\begin{array}{l}\text { Cutaneous leishmaniasis } \\
\text { (Lupoid form) }\end{array}\end{array}$ & 25 & $\begin{array}{l}\text { L. major }(\mathrm{n}=8) \\
\text { L. tropica }(\mathrm{n}=17)\end{array}$ \\
Visceral leishmaniasis & 5 & L. tropica \\
Viscerotropic leishmaniasis (VTL) & 3 & L. infantum \\
\hline
\end{tabular}

Sampling, examination, and culture. Samples were prepared from ulcer exudates of patients with CL, and visceral samples recovered from cryopreserved conditions (Nitrogen tank $-196^{\circ} \mathrm{C}$ ). All the samples were cultured in RPMI-1640 medium (Gibco, Germany) supplemented with $10-15 \%$ fetal bovine serum (Gibco, Germany), penicillin $(100 \mathrm{U} / \mathrm{ml})$ and streptomycin $(100 \mu \mathrm{g} / \mathrm{ml})$ and then incubated at $24-25^{\circ} \mathrm{C}$ [3].

DNA extraction and PCR-RFLP. DNA was extracted from promastigotes using the High Pure PCR Template Preparation Kit (Roche-Germany) according to the manufacturer's instructions. For identification of the species, the internal transcribed spacer1 (ITS1) sequence was amplified followed by the RFLP method as described previously [19].

RNA extraction and cDNA synthesis. Total RNA was extracted from the promastigotes during the stationary-phase by homogenization in a $1 \mathrm{ml}$ tripure reagent according to the manufacturer's instruction (Roche, Mannheim, Germany). For the elimination of DNA contamination, DNase1 (1 unit $/ \mu \mathrm{L})$ (Frementas, Ontario, Canada) was used for $45 \mathrm{~min}$ at $37^{\circ} \mathrm{C}$. cDNA synthesis was performed using the cDNA Synthesis Kit (Roche, Germany) and the integrity of cDNA evaluated with alpha-tubulin primers (F: CAGGTGGTGTCGTCTCTGAC) (R: TAGCTCGTCAGCACGAAGTG) as housekeeping gene [20].

Quantitative Real-Time PCR. The cysteine protease B (CPB) and alpha-tubulin genes were amplified by a RealTime PCR assay. The CPB primers, forward (5ACAGCTCCT-CTTTCATGGAC) and reverse (5AATGTGTGAGGA-CAGGTACG) were designed using the Primer 3 software version $0.4 .0 \mathrm{http}$ ://frodo.wi.mit.edu). The $20 \mu \mathrm{l}$ reactions contained $1 \mu \mathrm{l}$ cDNA target, $100 \mathrm{nM}$ forward and reverse primers and 1x SYBR® Premix Ex TaqTM II (Takara, Tokyo, Japan). The amplification was carried out in an Applied Biosystem step one (ABI company), programmed for $10 \mathrm{~min}$ at $94^{\circ} \mathrm{C}, 40$ cycles of $5 \mathrm{~s}$ at $94^{\circ} \mathrm{C}$ and $20 \mathrm{~s}$ at $60^{\circ} \mathrm{C}$ followed by a melt curve analysis using temperature increments of $0.2^{\circ} \mathrm{C}$ every $30 \mathrm{~s}$ to ascertain amplification of the expected product. The relative expression of the CPB gene was calculated by comparing the cycle thresholds (CTs) of the target gene with that of the 
housekeeping gene (Alpha-tubulin) using the relative expression software tool (REST, http://rest.genequantification.info) as previously described [21].

Data Analysis. The expression ratio results of the genes of interest were calculated for significance by a Pairwise Fixed Reallocation Randomization Test and calculated by REST. Samples with a probability value of $<0.05$ were considered significantly different among the groups. Statistical analysis between groups was performed using one-way analysis of variance (ANOVA). All experiments were conducted at least three times and the results were expressed as the mean \pm standard deviations (SDs.) [21].

\section{RESULTS}

Expression of CPB gene in different Leishmania species (interspecies). Real-time RT-PCR was used to determine the relative expression of CPB gene in the $L$. tropica, L. major and $L$. infantum. The mean expression of CPB gene in the isolates of $L$. tropica, $L$. major and $L$. infantum was $1.493,2.179$, and 3.022 , respectively ( $P$-value $<0.05)$. The highest level of RNA expression was observed in L. infantum isolates and the lowest in L. tropica isolates (Figure 1).

Expression of CPB in L. tropica isolates (Intraspecies). The average expression of the CPB gene was the highest in $L$. tropica isolates derived from lupoid forms ( $P$-value $<0.05)$. As shown in Fig. 2, the average expression of CPB was 23.78 in the isolates from lupoid forms $(n=3)$, which was 6.4 fold higher than that of non-lupoid $L$. tropica isolates $(n=17,3.68)$. There was no significant relationship between the CPB RNA expression among the L. tropica isolates, according to the number of ulcers, duration, and location of the infection, sex, and age (data not shown). Also, the average transcript expression of the CPB gene in L. tropica isolates derived from viscerotropic leishmaniasis cases $(n=3)$ was 3.03 which was not statistically significant compared to non-lupoid forms.

Expression of CPB in L. major isolates (Intraspecies). In L. major, as shown in Fig. 3, the highest expression was observed in the isolates obtained from patients who had 3, 2 , and 1 lesion, respectively. The RNA level of CPB was elevated in line with the increase of the ulcer's duration; in this line, the highest expression was exhibited in the isolates derived from ulcers occurred 3-5 months before the sampling. Additionally, CPB RNA transcript expression of L. major isolates did not differ by sex and age (data not shown).

Expression of CPB in $L$. infantum isolates (Intraspecies). The expression of the CPB gene was associated with the severity of the infection in 5 isolates of L. infantum. The highest expression was observed in an isolate obtained from a dog with an acute form of visceral leishmaniasis and a high titer of anti-leishmanial antibody (1: 5120) revealed by Direct Agglutination Test (DAT) while the lowest expression rate was observed in an isolate from a cat spleen (Fig. 4).

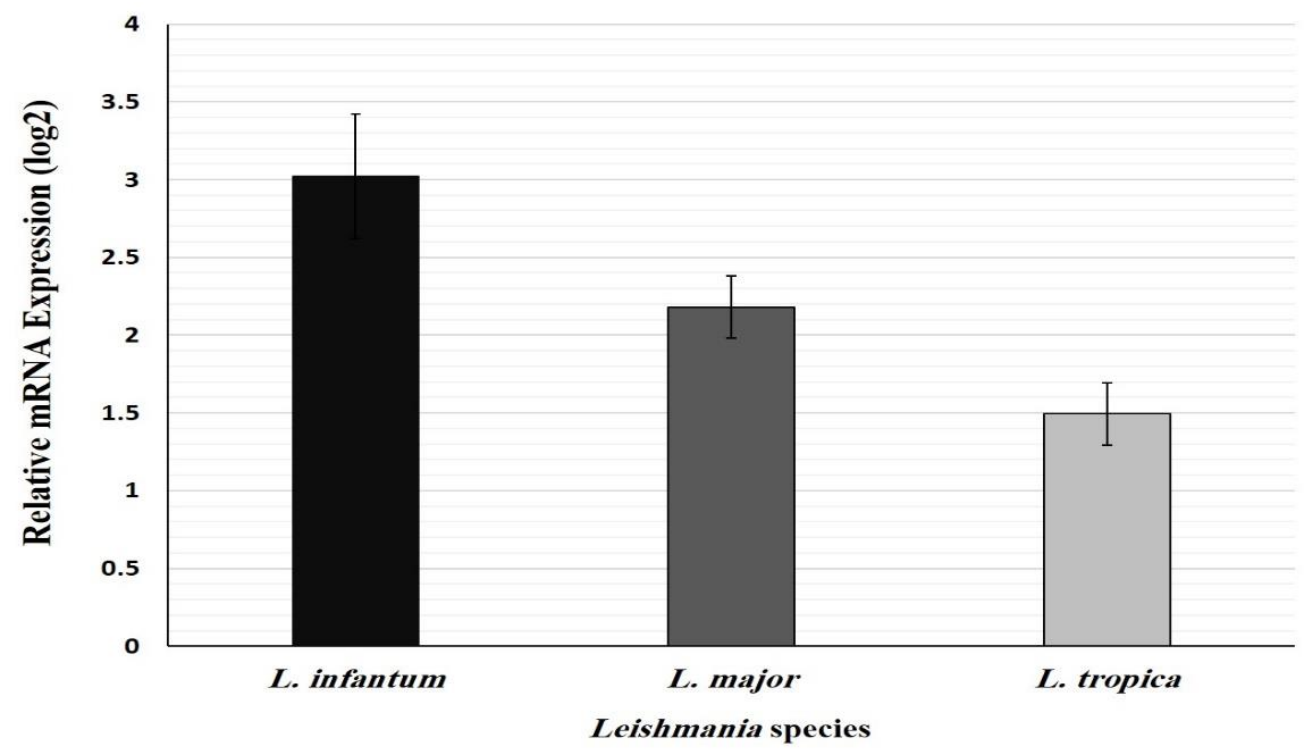

Fig. 1. Comparison of the mean of cysteine protease B gene (CPB) expression in isolates of different Leishmania species. The values are the mean $\pm \mathrm{SD}$ of two independent experiments. The mean expression of the CPB gene between Leishmania species is statistically significant $(P<0.05)$. 


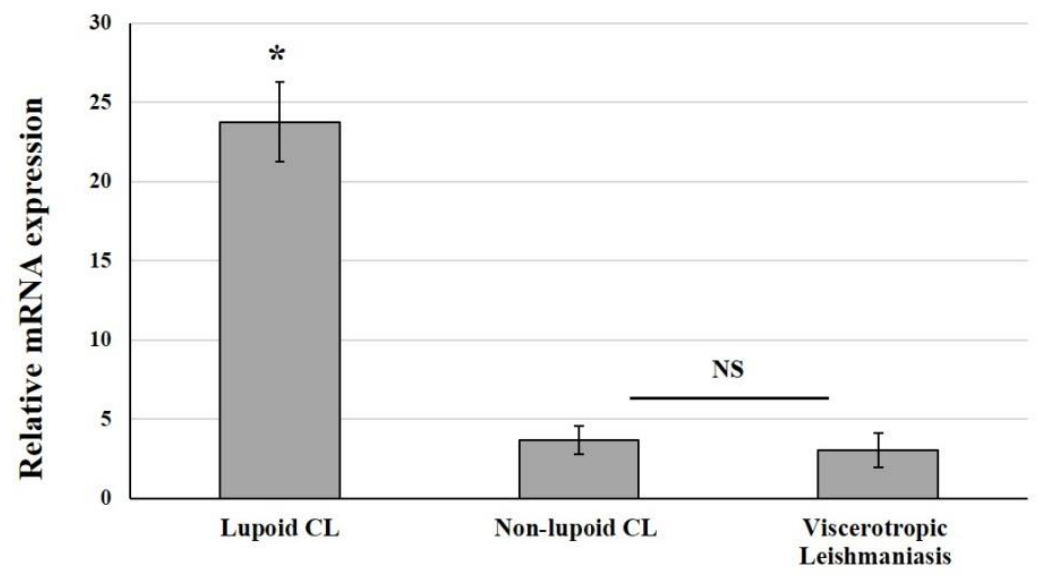

Clinical symptoms induced by $L$. tropica isolates

Fig. 2. Relative RNA expression of the CPB gene based on the clinical symptoms. The expression of alpha-tubulin was used to normalize the data. The values are the mean \pm SD of two independent experiments. *; Significantly different $(P<0.05)$; NS, non-significant. Lupoid CL cases ( $\mathrm{n}-3)$; Nonlupoid $(\mathrm{n}=17)$ and viscerotropic Leishmania $(\mathrm{n}=3)$.

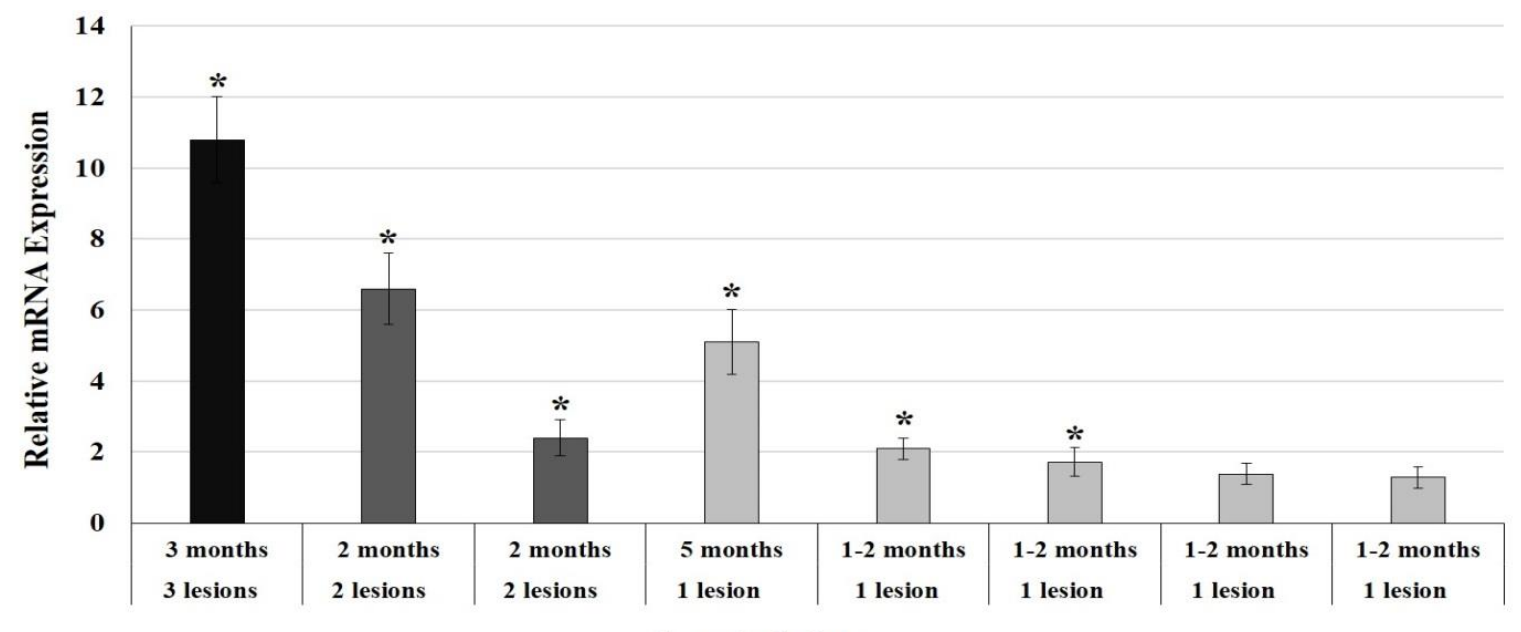

L. major isolates

Fig. 3. Relative mRNA expression of the CPB gene in 8 L. major isolates derived from CL patients according to the number and duration of ulcers (each column represents one patient). The expression of alpha-tubulin was used to normalize the data. The values are the mean \pm SD of two independent experiments. *Significantly different $(P<0.05)$.

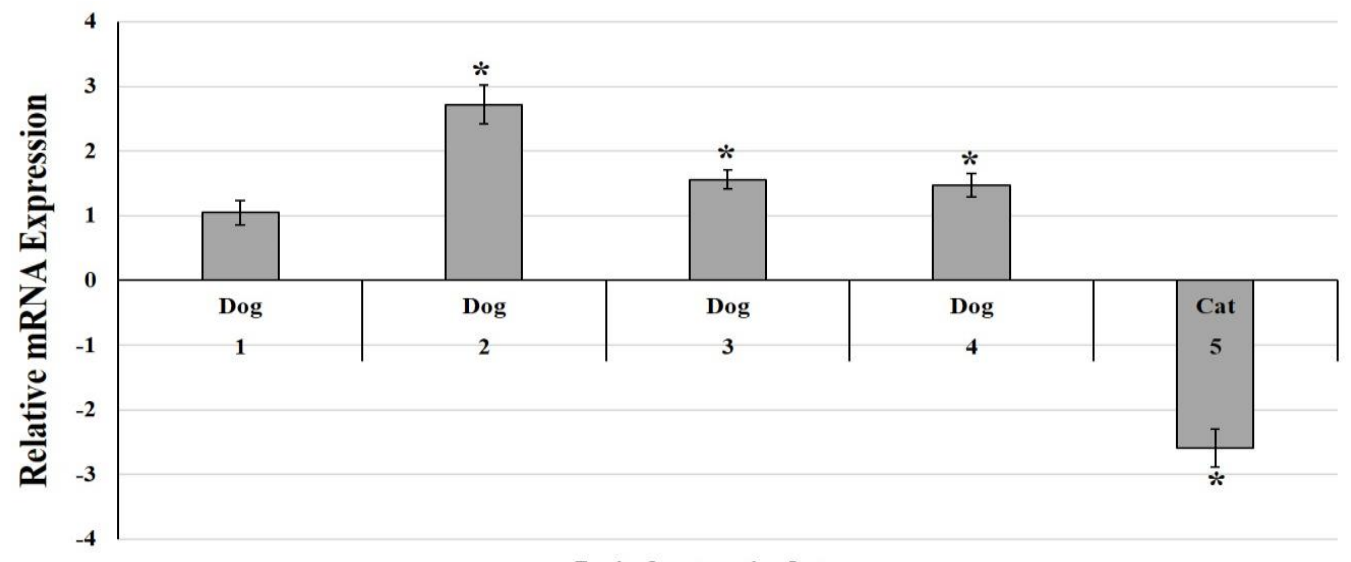

\section{L. infantum isolates}

Fig.4. The level of RNA expression of the CPB gene in 5 L. infantum isolates. The highest expression in the isolate (No. 2) obtained from a dog with acute VL and the lowest expression was in the isolate (No. 5) derived from a cat without clinical symptoms. The values are the mean \pm SD of two independent experiments. *Significantly different $(P<0.05)$ 


\section{DISCUSSION}

Several studies have examined changes in the expression of the Leishmania parasite gene during different stages of the parasite. These studies have shown that less than $5 \%$ of mRNA transcripts is dis-regulated during promastigote to amastigote differentiation. Also, it has been demonstrated that changes in the level of expression of virulence factors in different species of Leishmania parasites affect the pathogenesis of parasites [22, 23]. Among the virulence factors, cysteine proteases are enzymes known to play a pivotal role in the establishment of infection [24]. CPB is associated with a Th2 cytokine response by increasing IL-4 production, degrading the transcription factor NF- $\kappa \beta$ and IL12 , thereby diminishing the Th1 cytokine response [25, 26]. Regarding the importance of cysteine proteases, in this study, for the first time, the RNA expression of cysteine protease B (CPB) among different Leishmania species (interspecies) was investigated. Our results revealed that the level of RNA expression of CPB gene was the highest in $L$. infantum and L. major, respectively and the least in L. tropica. Among CL isolates, the average expression of CPB was significantly higher in L. major compared to L. tropica isolates. Since $L$. infantum-induced visceral form, (the most invasive leishmaniasis) and L. major induce a more devastating form of CL compared to L. tropica, the higher level of CPB expression is expected in these species. Moreover, in agreement with our findings, a study by Kariyawasam et al. [27] revealed that pooled virulence factors transcript was lower in $L$. (V.) panamensis isolates than that of $L .(V$. braziliensis and $L$. (V.) guyananesis at $24 \mathrm{~h}$ post macrophage infection, which might reflect that a strain of $L$. (V.) panamensis originated from a patient with non-severe CL while L. (V.) braziliensis isolates derived from more clinically invasive lesions. These findings suggested the most expression of virulence factors could be exhibited in the species inducing more severe clinical forms [27, 28].

In the current study, the RNA expression of the CPB gene among each of the isolates (Intraspecies) was investigated. In L. tropica isolates (Intraspecies) the lupoid-form isolates exhibited the highest expression compared to the isolates from non-lupoid and VTL. Moreover, the average expression of CPB was the least in L. tropica isolates derived from VTL and was approximately similar to that of non-lupoid isolates. The expression of this gene in the lupoid forms was approximately 6.4 times higher than that of non-lupoid $L$. tropica isolates, which is statistically significant $(P<0.05)$. As there is no biomarker that can predict the possibility of recurrence of the wound to prevent its occurrence, upregulation of CPB in lupoid forms could be suggested this gene as a potential biomarker to detect the possibility of recurrence and lupoid form; however, due to the limitation of lupoid samples further study on more clinical samples is needed to confirm our findings.

Among 8 L. major isolates, the transcript level of the CPB increased in the isolates derived from patients with a higher number and duration of ulcers. In this context, a correlation between the CPB expression and virulence has been reported in L. amazonensis promastigotes [29]. Also, the highest expression of $\mathrm{CPB}$ was reported in $L$. $(V$.) braziliensis isolates derived from more clinically invasive lesions in comparison with a strain of $L$. (V.) panamensis originated from a patient with non-severe $C L$, suggesting an association of clinical phenotype and expression level of virulence factors [27]. Likewise, our findings suggest a probable correlation between the duration of wound and CPB gene expression; however, since the progression of wound is multifactorial further analysis is needed to confirm it.

In visceral samples, $L$. infantum isolates displayed the highest CPB expression compared to the other species. Among $4 \mathrm{~L}$. infantum isolates drived from dogs, the highest expression was observed in a case with a high titer of antileishmaniasis by DAT. Consistent with our results, in a former study on $L$. viannia subgenus isolates, it was revealed that RNA expression level of CPB was upregulated during post-macrophage infection. These findings may associate with disease severity through reducing the Th1-directed cytokine profile and immunologic response to infection [30, 31].

It is worth mentioning that different clinical features are reported in CL or VL in several parts of the world in different hosts; nonetheless, many manipulating factors have not yet understood [32]. Several studies revealed that the genetic heterogeneity of parasite might induce diverse clinical manifestations [33, 34]. Besides, the immune system and immunodeficiency syndrome play a vital role in the clinical outcome and severity of the infection. It has also been reported that single nucleotide polymorphisms (SNPs) occurring in CPs, which can vary according to the parasite's life stage, could be related to clinical characteristics such as a dermotropic rather than a viscerotropic status [35].

The cysteine protease $\mathrm{B}$ gene (CPB) is expressed in the promastigote forms of all three species of $L$. tropica, $L$. major and L. infantum of Iran. As the results showed, the highest expression was in L. infantum, and then L. major and the least expression in L. tropica. The transcript level of CPB increased in $L$. major isolates derived from patients with a higher number and duration of ulcers. Further studies on more clinical samples are needed to explore our findings.

\section{ACKNOWLEDGMENT}

This study was financially supported by a grant from Tehran University of Medical Sciences (Projects No 93-0327-27047).

\section{CONFLICT OF INTEREST}

The authors declare that there are no conflicts of interest associated with this manuscript.

\section{REFERENCES}

1. Murray HW, Berman JD, Davies CR, Saravia NG. Advances in leishmaniasis. Lancet 2005; 366 (9496): 1561-77.

2. Magill AJ, Grögl M, Gasser RA Jr, Sun W, Oster CN. Visceral infection caused by Leishmania tropica in veterans of Operation Desert Storm. N Engl J Med. 1993; 328 (19): 1383-7. 
3. Hajjaran H, Mohebali M, Teimouri A, Oshaghi MA, Mirjalali $\mathrm{H}$, Kazemi-Rad E, et al. Identification and phylogenetic relationship of Iranian Strains of various Leishmania species isolated from cutaneous and visceral cases of Leishmaniasis based on $\mathrm{N}$ acetyl glucosamine-1-phosphate transferase gene. Infect Genet Evol. 2014; 26, 203-212.

4. Matlashewski G. Leishmania infection and virulence. Med Microbial Immunol. 2001; 190 (1-2): 37-42.

5. Silva-Almeida M, Pereira BA, Ribeiro-Guimarães ML, Alves CR. Proteinases as virulence factors in Leishmania spp. infection in mammals. Parasit Vectors. 2012; 7; 5: 160.

6. Verma S, Dixit R, Pandey KC. Cysteine Proteases: Modes of Activation and Future Prospects as Pharmacological Targets. Front Pharmacol. 2016; 7: 107.

7. Klemba M, Goldberg DE. Biological roles of proteases in parasitic protozoa. Annu Rev Biochem. 2002; 71: 275-305.

8. Sajid M, McKerrow JH. Cysteine proteases of parasitic organisms. Mol Biochem Parasitol. 2002; 120: 1-21.

9. Rafati S, Fasel N, Masina S. Leishmania cysteine proteinases: from gene to subunit vaccine. Curr Genom. 2003; 4, 109-121.

10. Mottram JC, Brooks DR, Coombs GH. Roles of cysteine proteinases of trypanosomes and Leishmania in host-parasite interactions. Curr Opin Microbiol. 1998; 1 (4): 455-60.

11. Poot H, Denise DC, Herrmann JC, Mottram GH, Coombs AN. Vermeulen, Virulence and protective potential of several Cysteine peptidase knockout strains of Leishmania infantum in hamsters, in: Poot J. Utrecht (Ed.), Experimental Challenge Models for Canine Leishmaniasis in Hamsters and Dogs, Optimization and Application in Vaccine Research, vol. 2006, Utrecht University press, Netherlands, 2006; 93e107.

12. Bañuls AL, Hide M, Prugnolle F. Leishmania and the leishmaniases: a parasite genetic update and advances in taxonomy, epidemiology and pathogenicity in humans. Adv Parasitol. 2007; 64: 1-109.

13. Khamesipour A, Rafati S, Davoudi N, Maboudi F, Modabber F. Leishmaniasis vaccine candidates for development: a global overview. Indian J Med Res. 2006; 123: 423-38.

14. Rafati S, Kariminia A, Seye Eslami S, Narimani M, Taheri T, Lebbatard M. Recombinant cysteine proteinase-based vaccine against Leishmania major in BALB/c: the role partial protection relies on interferon gamma $\mathrm{CD} 8+\mathrm{T}$ lymphocyte activation. Vaccine. 2002; 20: 2439-47.

15. Rafati S, Salmanian AH, Taheri T, Vafa M, Fasel N. A protective cocktail vaccine against murine cutaneous leishmaniasis with DNA encoding cysteine proteinases of Leishmania major. Vaccine. 2001; 14; 19 (25-26): 3369-75.

16. Rafati S, Nakhaee A, Tahere T, Ghashghaii A, Salmanian AH, Jimenez M, et al. Expression of cysteine proteinase type I and II of Leishmania infantum and their recognition by sera during canine and human visceral leishmaniasis. Exp Parasitol. 2003; 103: 143-51.

17. Nakhaee A, Taheri T, Taghikhani M, Mohebali M, Salmanian $\mathrm{AH}$, Fasel N, et al. Humoral and cellular immune responses against Type I cysteine proteinase of Leishmania infantum are higher in asymptomatic than symptomatic dogs selected from a naturally infected population. Vet Parasitol. 2004; 119: 107-123.

18. Coombs GH. Proteinases of Leishmania mexicana and other flagellate protozoa. Parasitology. 1982; 84: 149-155.

19. Hajjaran H, Mohebali M, Mamishi S, Vasigheh F, Oshaghi MA, Naddaf SR, et al. Molecular identification and polymorphism determination of cutaneous and visceral leishmaniasis agents isolated from human and animal hosts in Iran. Biomed Res Int. 2013; 2013: 789326.

20. Kazemi-Rad E, Mohebali M, Khadem-Erfan MB, Hajjaran H, Hadighi R, Khamesipour A, et al. Overexpression of ubiquitin and amino acid permease genes in association with antimony resistance in Leishmania tropica field isolates. Korean J Parasitol. 2013; 51: 413-419.

21. Pfaffl MW, Horgan GW, Dempfle L. Relative expression software tool (REST) for group-wise comparison and statistical analysis of relative expression results in real-time PCR. Nucleic Acids Res. 2002; 1; 30 (9): e36.

22. Kramer S. "Developmental regulation of gene expression in the absence of transcriptional control: the case of kinetoplastids." Mol Biochem Parasitol. 2012; 181 (2): 61-72.

23. Nafchi HR, Kazemi-Rad E, Mohebali M, Raoofian R, Ahmadpour NB, Oshaghi MA, et al. Expression analysis of viscerotropic leishmaniasis gene in Leishmania species by realtime RT-PCR. Acta Parasitol. 2016; 61 (1): 93-7.

24. Silva-Almeida M, Pereira BA, Ribeiro-Guimarães ML, Alves CR. Proteinases as virulence factors in Leishmania spp. infection in mammals. Parasit Vectors. 2012; 5 (1): 1-10.

25. Pereira BAS, Britto C, Alves CR. Expression of infectionrelated genes in parasites and host during murine experimental infection with Leishmania Leishmania amazonensis. Microb Pathog. 2012; 52 (2): 101-8 .

26. Mottram JC, Coombs GH, Alexander J. Cysteine peptidases as virulence factors of Leishmania. Curr Opin Microbiol. 2004; 7 (4): $357-81$.

27. Kariyawasam R, Mukkala AN, Lau R, Valencia BM, LlanosCuentas A, Boggild AK. Virulence factor RNA transcript expression in the Leishmania Viannia subgenus: influence of species, isolate source, and Leishmania RNA virus-1. Trop Med Health. 2019; 11; 47:25.

28. Ronet C, Beverley SM, Fasel N. Muco-cutaneous leishmaniasis in the New World. Landes Biosci. 2011; 2 (6): 54752 .

29. de Araújo Soares RM, dos Santos AL, Bonaldo MC, de Andrade AF, Alviano CS, Angluster $\mathrm{J}$, et al. Leishmania (Leishmania) amazonensis: differential expression of proteinases and cell-surface polypeptides in avirulent and virulent promastigotes. Exp Parasitol. 2003; 104 (3-4): 104-112.

30. Pereira BAS, Britto C, Alves CR. Expression of infectionrelated genes in parasites and host during murine experimental infection with Leishmania amazonensis. Microb Pathog. 2012; 52 (2): 101-8.

31. Aronson N, Herwaldt BL, Libman M, Pearson R, Lopez-Velez $\mathrm{R}$, Weina $\mathrm{P}$, et al. Diagnosis and treatment of Leishmaniasis: 
clinical practice guidelines by the Infectious Diseases Society of America (IDSA) and the American Society of Tropical Medicine and Hygiene (ASTMH). Clin Infect Dis. 2016; 63 (12): e202-64.

32. Convit J, Ulrich M, Pérez M, Hung J, Castillo J, Rojas H, et al. Atypical cutaneous leishmaniasis in Central America: possible interaction between infectious and environmental elements. Trans R Soc Trop Med Hyg. 2005; 99 (1): 13-17.

33. Schönian G, Akuffo H, Lewin S, Maasho K, Nylén S, Pratlong $\mathrm{F}$, et al. Genetic variability within the species Leishmania aethiopica does not correlate with clinical variations of cutaneous leishmaniasis. Mol Biochem Parasitol. 2000; 106 (2): 239-248.

34. Oryan A, Shirian S, Tabandeh M-R, Hatam G-R, Randau G, Daneshbod Y. Genetic diversity of Leishmania major strains isolated from different clinical forms of cutaneous leishmaniasis in southern Iran based on minicircle kDNA. Infect Genet Evol. 2013; 19: 226-231.

35. Hide M, Bañuls AL. Polymorphisms of cpb multicopy genes in the Leishmania donovani complex. Trans R Soc Trop Med Hyg. 2008, 102 (2): 105-106.

\section{Cite this article:}

Kazemirad E, Reisi Nafchi H, Latifi A, Raoofian R, Mohebali M, Hajjaran H. Comparison of Cysteine Protease B Gene Expression between Clinical Isolates of Leishmania tropica, Leishmania major and Leishmania infantum. J Med Microbiol Infect Dis, 2019; 7 (3): 72-78. DOI: 10.29252/JoMMID.7.3.72 